\title{
CRIAÇÃO DE CURTAS SOBRE ENGENHARIA CIVIL: A CIÊNCIA DO COTIDIANO
}

\author{
CREATING SHORT VIDEOS \\ ABOUT CIVIL ENGINEERING: \\ THE EVERYDAY SCIENCE
}

\section{RESUMO}

Este artigo apresenta o trabalho desenvolvido na chamada pública Projeto Forma Engenharia - CNPq/VALE S.A., visando o incentivo dos jovens para a engenharia. Por meio da produção de curtas, buscou-se produzir conteúdo para promover a divulgação científica da engenharia através da mídia. Os curtas produzidos ilustram conceitos de matemática, física e química, que ocorrem no dia a dia, em comparação com a aplicação desses fenômenos na área da Engenharia Civil. A equipe utilizou câmera de mão, softwares de animação e edição, e divulgação na internet. Ao todo, foram produzidos 10 vídeos, com uma linguagem de fácil assimilação para o público em geral. O número de acessos no site provou que este projeto é um meio eficiente e de baixo custo de divulgação científica, além de poder propiciar a participação dos discentes no processo de criação e de divulgação científica.

Palavras-chave: Divulgação científica; Integração universidade-escola; Mídias; Educação científica, Engenharia civil.

\section{ABSTRACT}

This study reports the project Forma Engenharia - CNPNALE S.A. which is aim to encourage young people to engineering career. It south to produce content to promote the popularization of engineering through the production of short videos that compares physics and chemistry concepts which occur in a daily basis to the phenomena that occur in Civil Engineering field. The videos were produced with hand-held camera, edited with animation and editing software, and disseminated through internet. In all, it was produced 10 videos in which the topics were demonstrated in a way that it is easily accessible to everyone. The number of access on the site proved that this project is an efficient and inexpensive means of scientific dissemination. Besides, it provides students an opportunity to take part in the creating process and in the scientific dissemination.

Keywords: Scientific dissemination; Integration university-school; Media; Science education; Civil engineering.

\footnotetext{
* Professor da Universidade Federal do Triângulo Mineiro (UFTM), MG - Brasil. E-mail: luciano@civil.uftm.edu.br

** Aluna de graduação da Universidade Federal do Triângulo Mineiro (UFTM), MG - Brasil. E-mail: camilla.vendramini@hotmail.com
} 
O crescimento econômico, deflagrado no Brasil nos últimos anos, foi fundamental para que vários projetos e investimentos fossem alavancados em praticamente todas as áreas e regióes do Brasil. Nesse contexto, as empresas sentiram dificuldade na contratação de mão de obra especializada, em especial engenheiros, pois o país vinha de uma grande recessão e estes profissionais mudaram de área ou de país, e também por este motivo não houve interesse dos jovens pelas carreiras na área de engenharia.

Buscando superar este quadro, a empresa VALE S.A. associou-se ao CPNq na elaboração de uma chamada pública, cuja intençáo era incentivar os jovens do ensino médio a seguirem a carreira no ensino superior nas áreas de engenharia, o que ajudaria a minimizar a carência deste profissional no futuro. Esta chamada pública se chamou Edital 05/2012 Projeto Forma Engenharia- CNPq/VALE S.A. Uma das linhas de pesquisa deste edital era a divulgação científica, em rádio e televisão, das atividades profissionais dos engenheiros. A partir desta premissa, foi desenvolvido este trabalho, para a produção de vídeos de curta duração para a divulgação científica na área de Engenharia Civil, com a participação de docentes e discentes da Universidade Federal do Triângulo Mineiro - UFTM e também de docentes e discentes do ensino médio da Escola Estadual Frei Leopoldo del Castelnuovo, ambos no município de Uberaba-MG.

A difusão científica (CAMARGO; BARBARÁ; BERTOLDO, 2008) se refere a todo o processo ou recurso utilizado para comunicar informaçóes científicas e tecnológicas. Quando a difusão científica é dirigida ao grande público, denomina-se divulgação científica. A divulgação científica é apresentada, na maioria das vezes, por meio de mídias tais como materiais didáticos, folhetos de campanha de saúde, spots de rádio, vídeos, televisão e, ultimamente, internet, que tem sido um instrumento muito eficaz de disseminação e de divulgaçáo da ciência. O material a ser produzido para a divulgaçáo científica deve possuir uma linguagem mais popular, para que o público, que não é especialista na área, possa assimilar com facilidade a mensagem transmitida.

Para se alcançar o sucesso na divulgação científica, é necessário - a priori - que a mídia a ser utilizada "prenda" a atenção do público-alvo. Uma das ferramentas mais poderosas é a imagem, pois como já dizia Confúcio, "uma imagem vale por mil palavras"; o vídeo nada mais é do que uma repetição de imagens que conta com a inserção de áudio, o que facilita bastante o entendimento da mensagem a ser divulgada. Uma produção audiovisual é altamente atraente para as pessoas, pois como diz Marília Franco (1997), "O bom é ver, espectar (sic). E definitivamente o prazer de verlouvir é a grande mágica sedutora das linguagens audiovisuais".

Com a utilização dos vídeos, pode-se aliar a divulgação científica ao entretenimento, fórmula muito utilizada em programas de divulgação científica da TV paga (NUNES, 2006), pois estes programas devem gerar lucro para se manter e a divulgação científica por si só não atrairia público suficiente para este fim. Os programas de divulgação científica da TV paga fazem com que as pessoas possam assistir a um vídeo em seu lugar preferido, fora do horário de trabalho, como uma diversão. A linguagem a ser utilizada nos vídeos de divulgação científica pela TV deve ser a mais simples possível, para que o público com baixa escolaridade entenda os conceitos científicos neles ilustrados.

Entretanto, muitas simplificações devem ser feitas, porém alguns conceitos científicos podem ser transmitidos de forma equivocada. Por outro lado, se for observado todo o rigor científico, não há tempo hábil para se transmitir a mensagem, a qual se torna muito complexa, podendo não atrair a atenção do público. A mensagem a ser transmitida em vídeo deve possuir um embasamento científico geral, de forma simples, sem se ater a preciosismos exigidos em cada caso.

A divulgação científica na TV aberta no Brasil teve início no ano de 1979, com o programa Nossa Ciência, idealizado pela TV Educativa do Rio de Janeiro, onde foram produzidos dez programas veiculados no horário nobre da sexta-feira (JURBERG, 2001). A abordagem utilizada correspondia a uma linguagem científica, pouco acessível a um público mais amplo, pois o formato era de uma mesa redonda 
onde vários especialistas de uma determinada área discutiam os temas pertinentes, mas com uma linguagem acadêmica, usando termos científicos desconhecidos pelo público em geral.

No início dos anos 1980, houve um boom de programas de divulgaçáo científica na TV aberta, como Estação Ciência (Manchete), Academia Amazônia (TV Cultura), Tome Ciência, Eco Realidade (Fundação Roquete Pinto), Universidade e Paidéia (TVEducativa) e Globo Ciência (TV Globo). O programa Globo Ciência é o único exibido até hoje e a formatação de sua programação apresenta uma grande exibição de imagens, possuindo uma linguagem mais popular, direcionada a desde um público não escolarizado até a comunidade científica e setores empresariais, embora a grande audiência do programa seja de adolescentes.

$\mathrm{Na}$ década atual, a produção de vídeos deixou de ser uma exclusividade das grandes redes de televisão, graças à diminuiçáo do preço e da alta qualidade das imagens produzidas pelas câmeras portáteis e smartphones. Graças a esta inovação tecnológica, várias pessoas podem produzir vídeos de boa qualidade e distribuí-los pela internet, em sites de divulgação gratuitos, como o youtube.com (YOUTUBE, 2005), atingindo a milhares de pessoas em uma escala global. Este recurso começa a ser utilizado também pelas escolas do ensino médio (TOLEDO, 2015), como forma de melhorar o aprendizado dos alunos e também para divulgação científica.

\section{Metodologia}

A equipe era composta por um professor do curso de Engenharia Civil, coordenador do projeto, uma docente do ensino médio que coordenava as atividades dos alunos do ensino médio, dois alunos bolsistas de curso superior e quatro alunos bolsistas do ensino médio, sendo todos esses alunos responsáveis pela produção e edição dos vídeos.

Para a divulgaçáo de atividades da área de engenharia civil, optou-se por pequenos vídeos, denominados "curtas", que foram produzidos com recursos tecnológicos de fácil acesso, adotando-se uma linguagem simples, mas com rigor científico, para que o público em geral entendesse a mensagem que se desejava transmitir. Os vídeos deveriam ter a duração entre um e três minutos, de modo que possam ser inseridos em intervalos da programação de TV e também não entediar o espectador.

A confecção de cada um dos curtas foi dividida em duas partes: a) a primeira parte diz respeito à escolha da temática, que foi definida a partir da observação de atividades cotidianas ou situaçóes comuns às pessoas e de como tais ocorrências estáo correlacionadas a atividades de engenharia civil, dando pistas sobre a relaçáo entre a atividade cotidiana e a profissional. A partir dessa contextualização, era lançada a questão: "- O que há de comum entre as duas atividades?"; b) na segunda parte, desenvolveu-se a explicação científica (física, química ou matemática) das atividades, correlacionando-se o que havia em comum. A ideia central foi a de mostrar, de forma muito didática, clara e acessível, que os conhecimentos físicos, químicos e matemáticos existentes em atividades corriqueiras seguem os mesmos princípios de quando utilizados para os grandes trabalhos no campo da engenharia civil.

Os vídeos foram produzidos de forma simples e, por esta razão, optou-se por utilizar uma câmera de mão, pois é de fácil manuseio, produz imagens com uma resolução 
muito boa, e também os vídeos produzidos poderiam ser facilmente editados em um computador pessoal.

O objetivo deste trabalho foi o de produzir curtas que ilustram as relaçóes entre as atividades de engenharia civil com as atividades do cotidiano das pessoas, no intuito de incentivar os jovens a seguirem a profissão de engenharia civil e também informar ao público em geral que muito das atividades de engenharia civil e do cotidiano podem ser explicados de uma maneira simples, direta e atraente.

$\mathrm{O}$ roteiro da produçáo dos vídeos seguiu as seguintes etapas:

\section{Escolha dos temas}

Em reunióes semanais, era apresentada a ideia do próximo vídeo, sendo que os temas deveriam tratar de atividades rotineiras das pessoas e descrever sob a ótica da física, química ou matemática o que estava acontecendo com este processo. Discutia-se sobre a maneira mais simples e didática de apresentar a temática escolhida, considerando-se como possibilidades filmes ou animaçóes gráficas, utilizando-se de uma linguagem simples e acessível, descartando-se recorrer a termos técnicos muito complicados.

O conhecimento científico apresentado nos vídeos deveria ser de fácil entendimento para qualquer pessoa, mesmo com uma escolarização mínima (ensino básico). Outro fator considerado foi a necessidade de ilustrar construçôes de engenharia civil, como barragens, pontes, fundações e grandes edificações, para incentivar principalmente os jovens do ensino médio a seguirem a carreira de engenharia civil.

Nesta fase, era elaborado todo o planejamento acerca dos recursos que deveriam ser utilizados na produção do vídeo, que na sequência deveriam ser providenciados pela equipe; eles dizem respeito aos materiais, à definiçáo dos locais da filmagem e ao detalhamento de toda a atividade, bem como da necessidade da utilizaçáo de animaçóes gráficas para a produçãa e edição do vídeo.

\section{Produçáo dos vídeos}

Com todo o roteiro detalhado, a equipe iniciava a produção dos vídeos. Algumas atividades eram filmadas e aconteciam no laboratório de ciências da Escola Estadual Frei Leopoldo, onde os atores eram os próprios alunos da escola. Outras imagens, como obras de edificações, fundaçóes e pontes eram filmadas externamente, e, ainda, algumas eram feitas nos laboratórios do curso de Engenharia Civil da UFTM.

Por se tratar de imagens em que seria necessário inserir gráficos para elucidar eventos físicos, algumas atividades foram executadas por animaçôes gráficas, sendo utilizado um software específico para esta atividade. Dentre os softwares procurados, alguns não possuíam licença livre e foram descartados por não haver previsão de compra de licença na proposta enviada ao $\mathrm{CNPq}$; outros softwares livres náo atendiam em termos de qualidade para a produção dos vídeos, pois possuíam falhas na animação e alguns produziam apenas imagens em 2D.

Dessa forma, o software escolhido foi o BLENDER (BLENDER, 2013), pela razáo de ter licença de uso gratuito, produzir excelentes imagens tridimensionais e também possuir uma gama muito variada de recursos de animação gráfica, como linha de tempo bem definida, ótima renderização de imagens, em especial na criação e movimentação de fluídos, modelagem de explosóes, dentre outros. $\mathrm{O}$ único inconveniente deste software deveu-se ao fato de estar escrito na língua inglesa, o que acarretou, para os alunos do ensino 
médio, certa dificuldade. Também por ser um software livre, a operação das atividades se processa por métodos diferentes dos tradicionais (os comandos são executados por teclado e não por mouse), o que retardou a produçáo das animaçóes gráficas, gerando um atraso na montagem dos vídeos.

Nos softwares de animação, a utilização de bibliografia tradicional de livros e tutoriais é de pouca ajuda, pois as animaçóes são dinâmicas e apresenta várias fases. Para este Projeto, foram utilizados tutoriais de vídeos do site youtube.com, que mostram o "passo a passo" de cada processo de animaçấo. O site mais visualizado foi o da autora Poggueti (2015).

Estando os vídeos prontos, foram gravados os áudios - que seriam posteriormente inseridos nos filmes - em notebooks e smartphones dos membros da equipe, em formato MP3, escolhido pela facilidade da inserção e edição de áudios nos vídeos.

A última etapa na produção dos vídeos foi a montagem final dos filmes, das animaçóes gráficas e do áudio. $\mathrm{O}$ software escolhido para esta montagem foi o MOVEMAKER (MOVEMAKER, 2013), de propriedade da Microsoft e que está disponível nos sistemas operacionais Windows 7. Este software possui interface gráfica bastante amigável e já é bem conhecido dos alunos do ensino médio, portanto, não houve grandes problemas na edição dos vídeos. Esta fase de ediçáo é muito parecida com a edição de filmes tradicionais, onde partes dos filmes são cortadas e há inserção de outras partes (filmagens ou animaçôes gráficas). Também há como sincronizar o áudio com as animaçôes gráficas e também inserir legendas e os créditos da equipe.

\section{Resultados}

No total, foram produzidos dez vídeos com tempo entre 1:12 a 3:14 minutos, que retrataram as mais variadas áreas da engenharia civil, como estruturas, fundaçóes, geotecnia, hidráulica e construção civil, relacionando-as com atividades do dia a dia das pessoas. Para ilustrar o produto final do trabalho, são apresentadas algumas das cenas principais do segundo e do quarto vídeos produzidos e, também, uma breve descrição do roteiro destes vídeos.

\section{Vídeo: Atrito}

Neste vídeo, são ilustrados os princípios físicos que explicam como um prego cravado adere em um pedaço de madeira e como as fundaçóes de estacas interagem com o solo para suportar o peso de grandes edificaçóes. Na primeira parte do vídeo, é ilustrada uma situação bastante comum e rotineira em um canteiro de obras, que é a cena de um operário cravando um prego em um pedaço de madeira, com o auxílio de um martelo (Figura 1). 


\section{Figura 1 - Operário da construçáo civil pregando um prego}

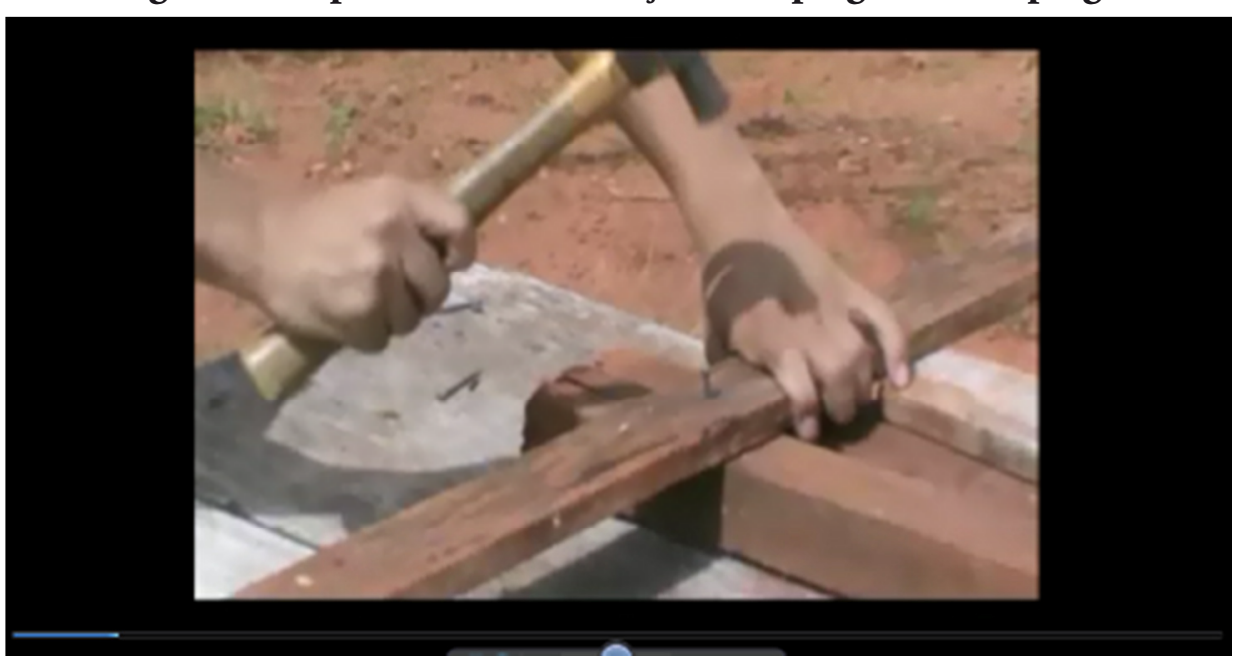

Fonte: Autor

Em sequência, é executado um corte brusco no vídeo e é apresentada outra atividade de Engenharia Civil, onde aparece um bate-estaca cravando uma estaca de fundação no solo (Figura 2).

Figura 2 - Cravação de estaca com auxílio de um bate-estaca

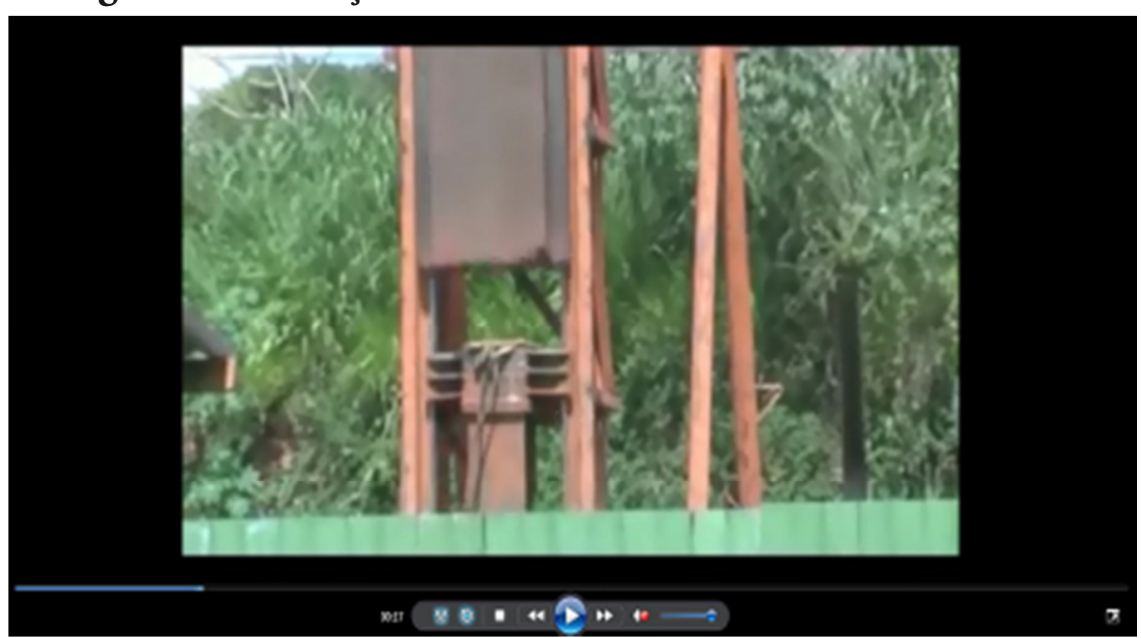

Fonte: Autor

Em seguida, é feito o seguinte questionamento na forma de áudio: - O que há de comum entre um prego e uma estaca de fundação?

$\mathrm{Na}$ segunda fase do vídeo, é ilustrado o princípio físico das duas atividades e feita a correlação entre elas. A Figura 3 ilustra o desenvolvimento do atrito lateral entre o prego e a madeira, que é a força que faz com que o prego se prenda a madeira, impedindo sua remoção. 


\section{Figura 3 - Vetores ilustrando o atrito lateral entre o prego e a madeira}

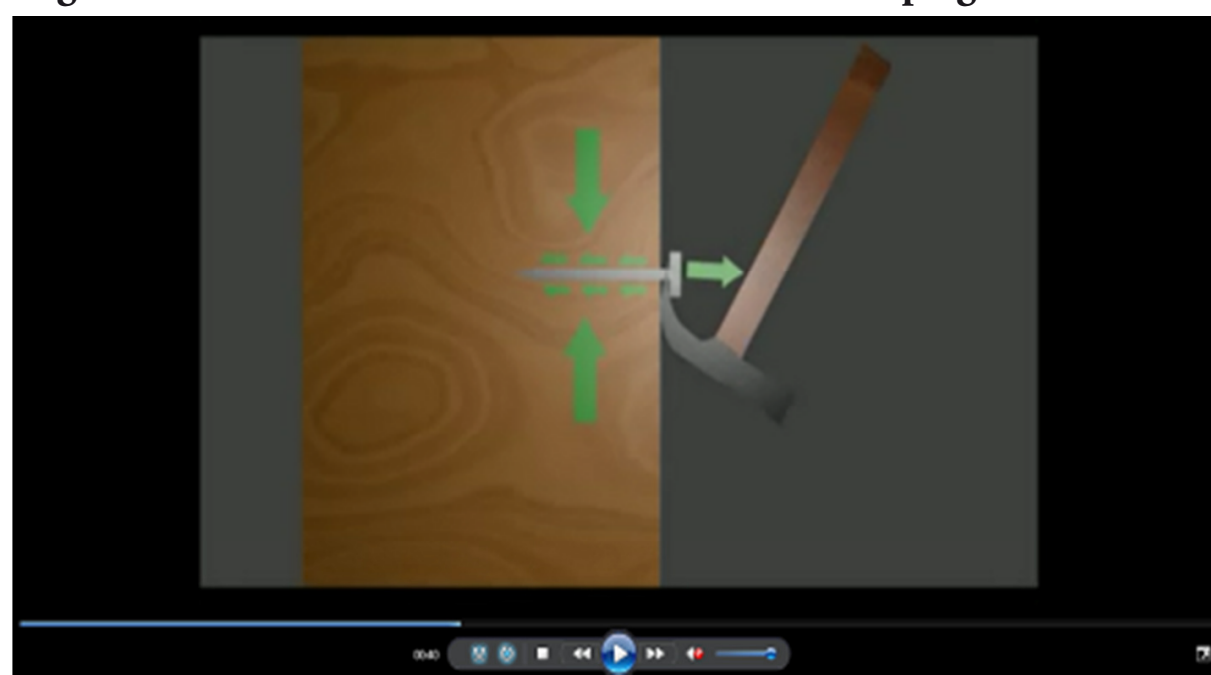

Fonte: Autor

Nesta fase, foram feitas animaçóes gráficas, onde foi mostrado o atrito lateral entre o prego e a madeira na forma de vetores (setas). A movimentação da animação foi importante para ilustrar como se dá a perda do atrito entre os materiais. Para os alunos do Projeto, este conceito foi explicado utilizando-se uma bibliografia utilizada por eles, ou seja, uma apostila do ensino médio (MEDEIROS; BARBOSA, 2015).

Já na Figura 4, é ilustrado o desenvolvimento do atrito lateral entre o solo e a estaca, que faz com que esta fundaçáo sustente a edificação acima, utilizando para esta explicação uma bibliografia específica para o curso de Engenharia Civil (BOWLES, 2001). Nesta animação, é frisado que é a pressão lateral do solo que faz com que surja o atrito entre o solo e a estaca, mostrando o que acontece de forma análoga à animação vista anteriormente do prego em relaçáo à madeira.

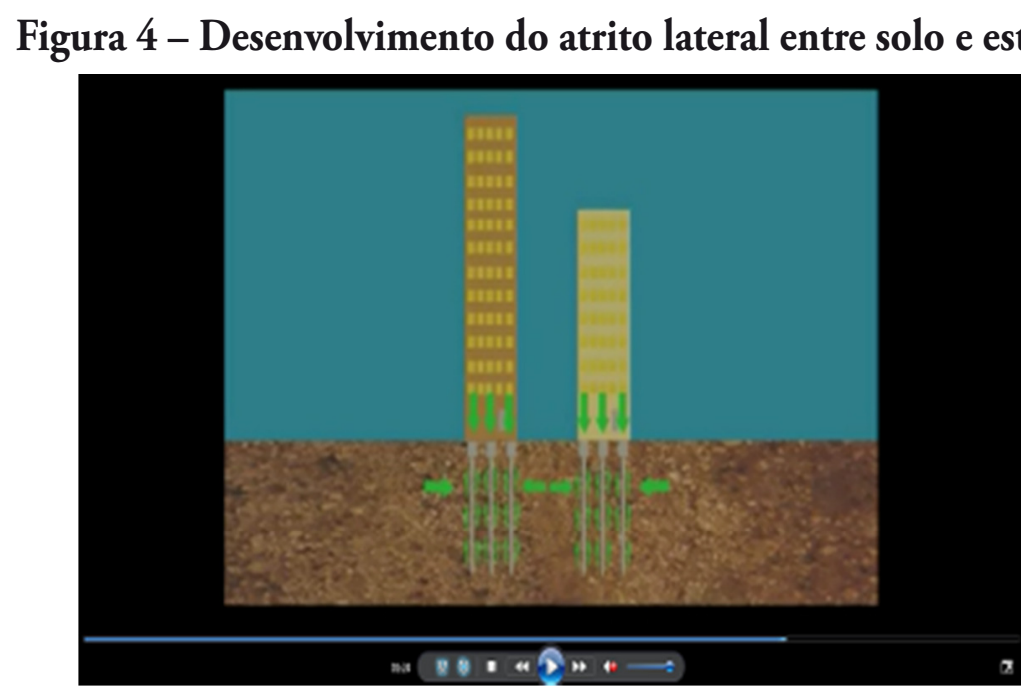

Fonte: Autor

Conclui-se, analisando a Figura 3 e a Figura 4, que o princípio físico entre as duas atividades é o mesmo. Toda essa sequência é explicada no vídeo, detalhadamente e com uma linguagem simples, acessível ao público em geral. 


\section{Vídeo: o caminho das águas}

Neste vídeo, foi feita uma analogia entre a infiltração de água em uma simples esponja de lavar louça e a infiltração da água da chuva no solo. O conceito físico aqui ilustrado será a percolação da água entre os vazios existentes na esponja e também no solo, que se dá pelo processo chamado de capilaridade. A primeira parte do vídeo mostra uma pessoa molhando uma esponja e depois a apertando para a água escorrer (Figura 5).

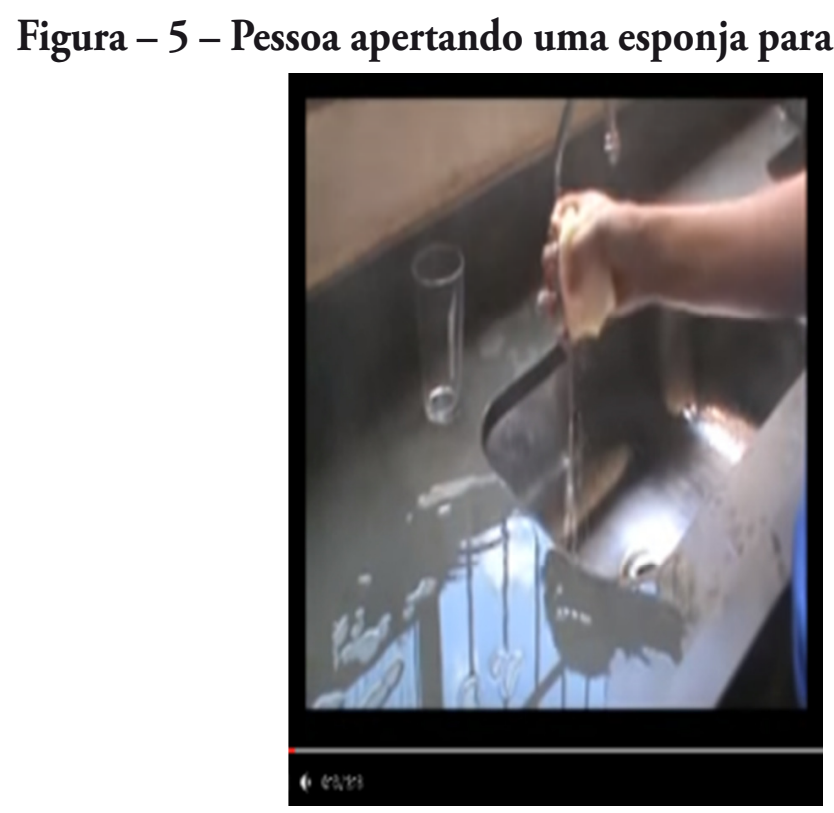

Fonte: Autor

Ao mesmo tempo, é feito um corte no vídeo onde aparece uma mina d'água (Figura 6) e é feita a seguinte pergunta: - O que há em comum entre uma simples esponja de lavar louça e uma mina d'água?

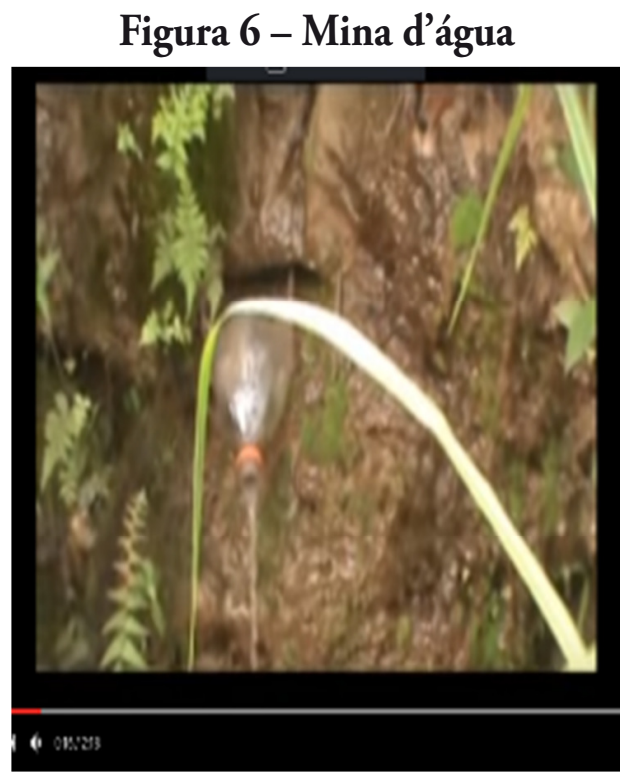

Fonte: Autor 
$\mathrm{Na}$ segunda fase do vídeo, é mostrada a animação gráfica que explica fisicamente o processo da esponja, informando que, quando a esponja foi molhada, alguns poros ficam cheios de água e outros não. Mas quando a pessoa aperta a esponja, os poros se juntam, diminuindo o espaço ocupado pela água, o que faz com que a água escorra entre os poros (Figura 7), e pela ação da gravidade começa a escorrer da esponja. Nesta fase, há a presença de um áudio que explica todo o processo.

Figura 7 - Água escorrendo dos poros de uma esponja após a contraçáo da mesma

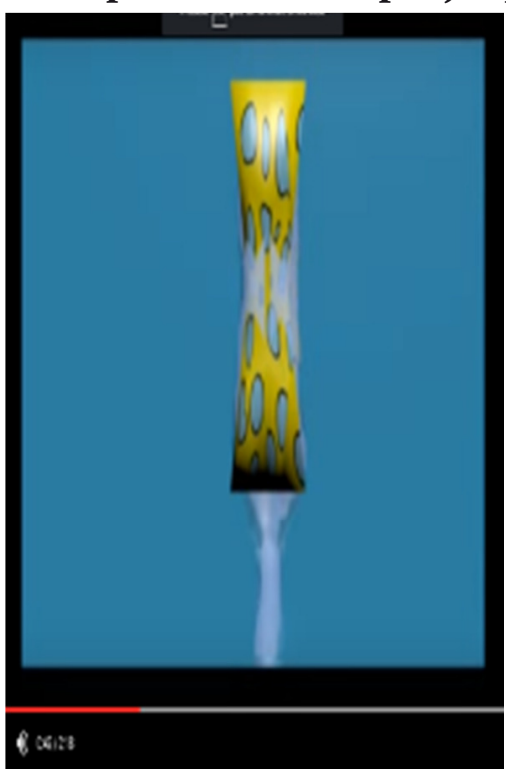

Fonte: Autor

Por último, é ilustrado um perfil de solo onde há uma chuva (Figura 8), situação análoga à primeira cena, onde uma pessoa está molhando a esponja.

Figura 8 - Água da chuva infiltrando no solo

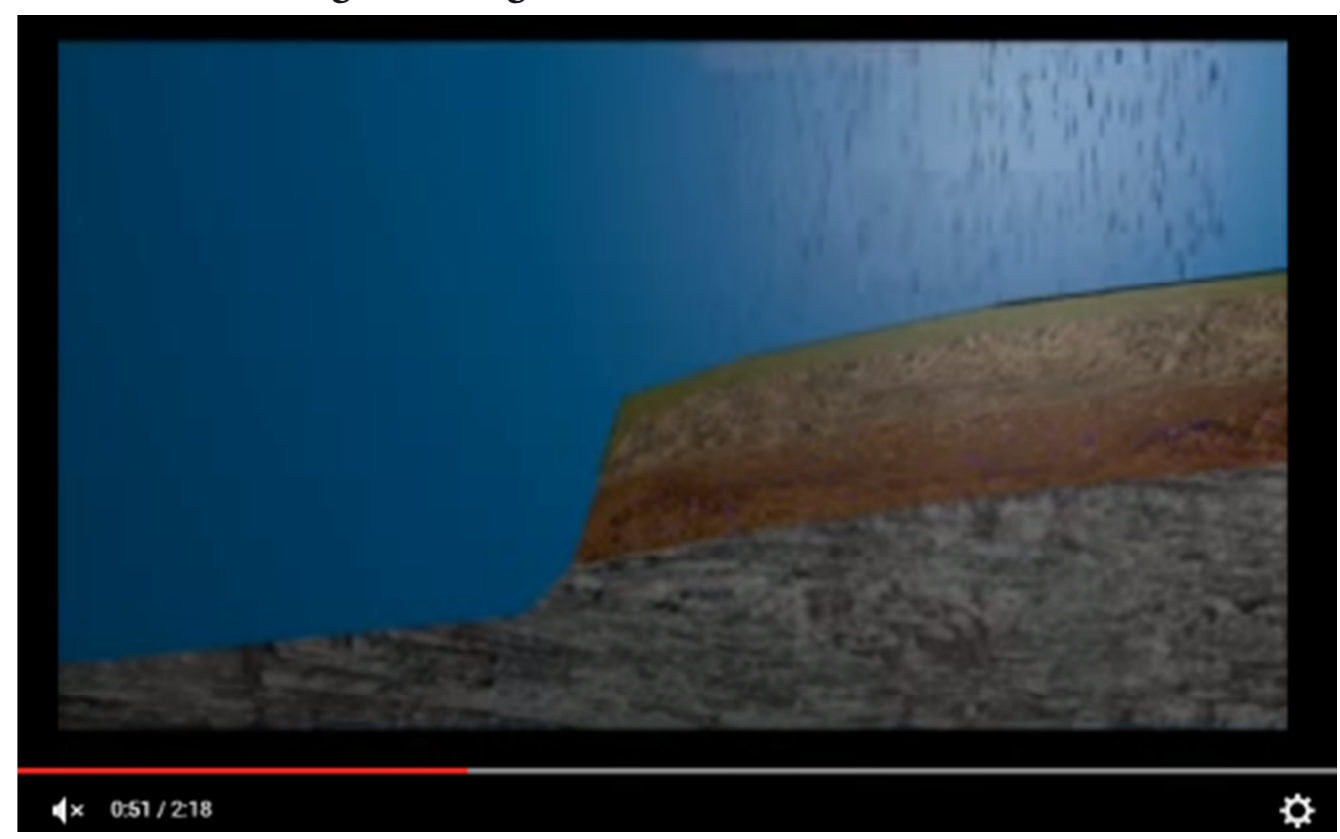

Fonte: Autor 
É ilustrado no vídeo o processo em que a água da chuva infiltra no solo e é contida por uma camada impermeável de rocha, ficando na camada permeável (a camada do meio entre as três camadas mostradas no vídeo) (Figura 9).

\section{Figura 9 - Percolaçáo de água no solo}

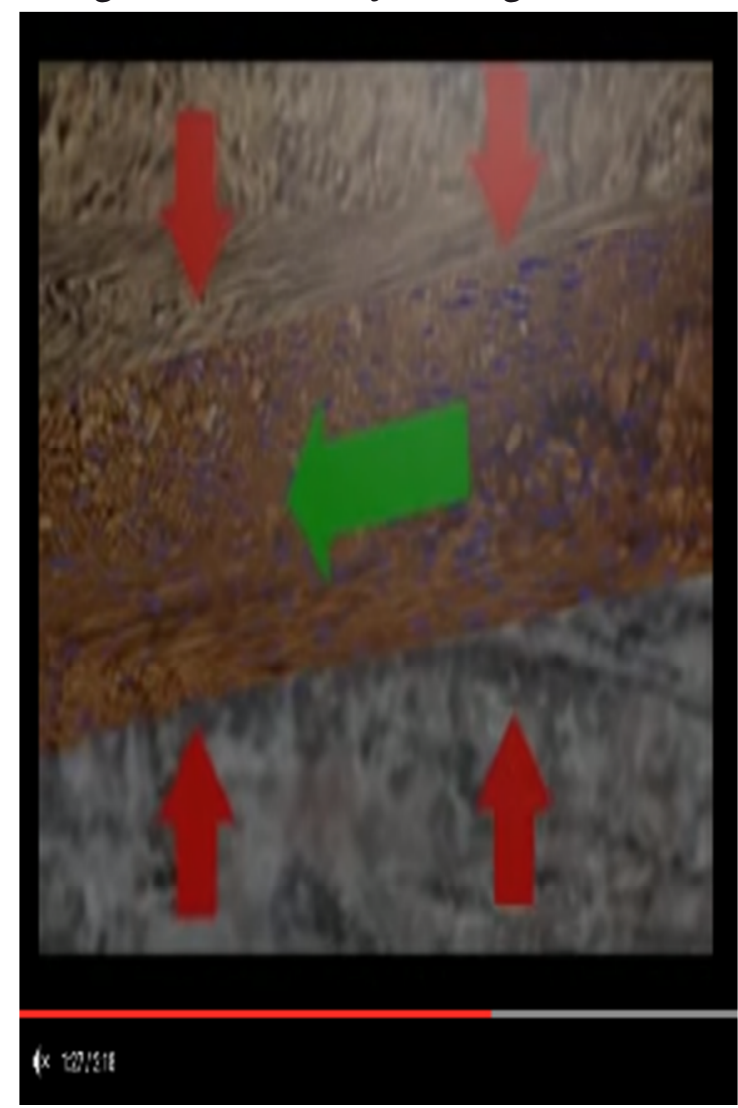

Fonte: Autor

Pela pressão exercida pelo solo superior à camada permeável e também pela impossibilidade de haver infiltração na rocha, o que é demonstrado pelas setas vermelhas, o solo se comprime e expulsa a água de seus poros que, pela ação da gravidade, escorre para pontos mais baixos do terreno (setas verdes). Onde houver uma exposiçáo destas camadas com a atmosfera, essa água escorrerá para fora, dando origem às minas d'água, em um processo análogo ao de uma pessoa apertar a esponja. Todo este processo é explicado em áudio no vídeo, em uma linguagem simples e de fácil assimilação para o público em geral.

\section{Divulgaçáo}

Os vídeos produzidos foram armazenados para serem posteriormente divulgados. Inicialmente, como descrito na proposta inicial, os vídeos deveriam ser divulgados nos intervalos da TV aberta, em especial da TV Universitária de Uberaba, a qual é mantida pela Universidade Federal do Triângulo Mineiro - UFTM. Entrando em contato com os diretores de programaçáo, foi-nos informado que tal inserçẫo na programação era paga, como acontece em toda a TV aberta, pois toda a programaçáo televisiva da TV aberta é mantida através de propaganda paga. Havia um edital de fluxo contínuo na Universidade 
para financiar tais atividades, mas náo atendia ao Projeto, pois os vídeos necessitavam de inserçôes constantes e o edital financiava uma ou poucas inserçóes.

A solução encontrada foi a divulgação na Internet, já que é uma mídia muito desenvolvida e bastante acessível à grande camada da populaçáo, tanto em computadores como em aparelhos móveis, como smartphones e tablets, pois como indica a pesquisa sobre a proporção de domicílios com acesso a internet no Brasil, feita pelo Centro Regional de Estudos para o Desenvolvimento da sociedade de Informação - (CETIB, 2014), 54\% dos lares brasileiros possuem acesso a internet. $\mathrm{O}$ canal escolhido foi o youtube.com, que já é certamente o canal de vídeo de divulgaçáo gratuito mais conhecido no mundo. Foi aberto um canal onde foram publicados os dez vídeos produzidos. $\mathrm{O}$ endereço dos vídeos está descrito a seguir:

\begin{tabular}{|l|c|l|c|}
\hline TíTULO & Tempo em min. & LINK & Visitas* \\
\hline $\begin{array}{l}\text { 1- Casamento Perfeito } \\
\text { (Concreto armado)** }\end{array}$ & $3: 04$ & $\begin{array}{l}\text { https://www.youtube.com/ } \\
\text { watch?v=SXT7TpDv1s8 }\end{array}$ & 308 \\
\hline $\begin{array}{l}\text { 2- Lego (Estrutura pré- } \\
\text { fabricada) }\end{array}$ & $1: 52$ & $\begin{array}{l}\text { https://www.youtube.com/ } \\
\text { watch?v=XsuTpqvNyOM }\end{array}$ & 40 \\
\hline 3- Atrito & $1: 54$ & $\begin{array}{l}\text { https://www.youtube.com/ } \\
\text { watch?v=FawmAuoON70 }\end{array}$ & 945 \\
\hline $\begin{array}{l}\text { 4- Conhecendo o que não se } \\
\text { vê (Sondagem do subsolo) }\end{array}$ & $3: 27$ & $\begin{array}{l}\text { https://www.youtube.com/ } \\
\text { watch?v=TO2q0DymLWI }\end{array}$ & 799 \\
\hline $\begin{array}{l}\text { 5- Distribuição de peso } \\
\text { (Fundações rasas) }\end{array}$ & $1: 34$ & $\begin{array}{l}\text { https://www.youtube.com/ } \\
\text { watch?v=8pE_lqMewkU }\end{array}$ & 357 \\
\hline $\begin{array}{l}\text { 6- De um copo d'água aos } \\
\text { grandes rios (Fundações } \\
\text { profundas) }\end{array}$ & $2: 17$ & $\begin{array}{l}\text { https://www.youtube.com/ } \\
\text { watch?v=xRCgL3FRnSg }\end{array}$ & 30.888 \\
\hline $\begin{array}{l}\text { 7- A receita (Materiais de } \\
\text { construção civil) }\end{array}$ & $1: 12$ & $\begin{array}{l}\text { www.youtube.com/watch?v=- } \\
\text { l7OyR8VeNY }\end{array}$ & 1.071 \\
\hline $\begin{array}{l}\text { 8- O caminho das águas } \\
\text { (Hidráulica) }\end{array}$ & $2: 19$ & $\begin{array}{l}\text { www.youtube.com/ } \\
\text { watch?v=5LcDMKFIL8I }\end{array}$ & 2.710 \\
\hline $\begin{array}{l}\text { 9- Do cafezinho à energia } \\
\text { elétrica (Hidráulica e } \\
\text { geotecnia) }\end{array}$ & $2: 03$ & $\begin{array}{l}\text { https://www.youtube.com/watch?v=w0- } \\
\text { TotITZyU }\end{array}$ & 4.011 \\
\hline $\begin{array}{l}\text { 10- Fadiga (pontes) } \\
\text { https://www.youtube.com/ } \\
\text { watch?v=APPX_irGEpM }\end{array}$ & 601 \\
\hline
\end{tabular}

Nota: visitas entre os dias 24/05/2015 até o dia 23/03/2016. ** Em parênteses, as áreas correlatas de Engenharia Civil mostradas nos vídeos.

\section{Conclusáo}

A ideia principal deste trabalho foi a produção de vídeos que ilustram, de forma simples e didática, os conhecimentos científicos inclusos nas atividades cotidianas das pessoas e sua relação com atividades desenvolvidas no campo da engenharia civil, tornando atraente para o público. $\mathrm{O}$ formato de curta foi escolhido por não ocupar tanto tempo de espectador.

Os vídeos são de fácil entendimento para o público em geral, pois apresentaram uma linguagem simples, do dia a dia das pessoas, utilizando expressóes linguísticas populares. A linguagem científica adotada segue os padrôes de canais televisivos de divulgação científica da TV paga, com farta ilustraçáo gráfica para explicar cientificamente os eventos 
ilustrados. Este efeito foi conseguido graças aos poderosos recursos do software blender. As filmagens foram feitas como um vídeo amador, com equipamentos de baixo custo e de alta eficiência e qualidade, pelos próprios alunos.

A forma de divulgação escolhida foi a de hospedar todo o material produzido no site youtube.com, que apresenta, além da gratuidade de acesso, um canal de diálogo com o público. Este site é referência mundial na disseminaçáo de vídeos caseiros e conhecido de todos os internautas, o que faz com que seja visualizado por um grande número de pessoas. No período compreendido entre os dias 24/05/2015 e 23/03/2016, 41.730 pessoas já visualizaram os vídeos, o que atesta a sua boa aceitação.

Em suma, os vídeos atingiram o objetivo proposto pelo Projeto, que foi a divulgação de atividades de Engenharia Civil para o público, em especial para jovens do ensino médio, neste caso para incentivar o ingresso nos cursos de Engenharia Civil

Este projeto mostrou que é possível que os alunos produzam, podendo ser feitas até com smartphones e editados em softwares livres em microcomputadores. Com estes recursos, é possível a produção de vídeos sobre as mais variadas matérias do ensino médio, como matemática, física, geografia e português, sendo atrativo para os jovens do ensino médio, que já produzem vídeos e os publicam na Internet.

O software blender se mostrou muito trabalhoso de se operar, por razáo de seus comandos estarem escritos na língua inglesa, mas esta dificuldade pode ser utilizada principalmente como um desafio de atividades das disciplinas da língua inglesa. As escolas de ensino médio poderiam oferecer mini-cursos ou atividades de montagem de animaçóes gráficas, nos quais os jovens têm grande interesse.

O canal de divulgaçáo youtube.com poderia ser mais utilizado pelas escolas, com a criação de um canal próprio para veicular atividades escolares, além de material didático produzido internamente por meio de vídeo aulas, animaçóes e outras atividades didáticas.

\section{Agradecimentos}

Agradecemos ao CNPq e a VALE S.A. (Chamada pública Edital 05/2012 Projeto Forma Engenharia - CNPq/VALE S.A.) e a CAPES (Programa Jovens Talentos) pelo auxílio financeiro na execução do projeto.

\section{Referências}

BARROS, H. L. A cidade e a ciência. In: MASSARANI, L; MOREIRA, I. C.; BRITO, F. (Eds.). Ciência e público: Caminhos da divulgação científica no Brasil. Rio de Janeiro, RJ: Centro Cultural de Ciência e Tecnologia da Universidade Federal do Rio de Janeiro, 2002. p. 25-42.

BLENDER Software de criação de animações gráficas no espaço tridimensional. Blender Foundation, Germany. Software. Disponível em: <https://www.blender.org/ about/>. Acesso em: 14 jul. 2013.

BOWLES, J. Foundation analysis and design. McGraw Hill. $5^{\text {th }}$ Edition. New York, 2001. 
CAMARGO, B. V.; BARBARÁ, A.; BERTOLDO, R. B. A influência de vídeos documentários na divulgação científica de conhecimento sobre a Aids. Psicologia: Reflexão e Crítica, v. 21, n. 2, 2008.

CETIB Tic Domicílios e Usuários 2014, A4- Proporção de domicílios com acesso a Internet, 2014. Disponível em: <www.cetic.br/usuarios/2014/total-brasil/A4/>. Acesso em: 23 mar. 2016.

FRANCO, M. Linguagens audiovisuais e cidadania. Comunicação \& Educação, São Paulo, v. 9, p. 32-55, 1997.

JURBERG, C. Ciência na TV: um erro histórico. INTERCOM - Sociedade Brasileira de Estudos Interdisciplinares da Comunicação. In: CONGRESSO BRASILEIRO DA COMUNICAÇÃO, XXIV, Campo Grande /MS, set. 2001.

MEDEIROS, A. F.; BARBOSA, C. G. Física: O movimento e suas causas. Módulo 2. São Paulo: Editora FTD, ano. pp. 13-15.

MOVEMAKER, Software de edição gráfica. Edita filmes com a inclusão de filmes, animações e áudio. MICROSOFT. Software. Acesso em: 02 nov. 2013. 
NUNES, C. Ciência e TV, a união possível e desejável. Cienc. e Cult., 2006. v. 58, n.4, p. 10-11, 2006.

POGGUETI, I. Curso de Blender. Disponível em: http://www.equilibrecursos.net/. Acesso em: 12 jan-12 dez 2013.

TOLEDO, L. F. Luz câmera e ação: ficção do cinema vira realidade na escola. Jornal O Estado de São Paulo, 2015, São Paulo - SP. Edição 06/09/2015.

YOUTUBE, Apresenta vídeos na internet gratuitamente dos mais variados campos da cultura. Google 2005-2016. Software. Disponível em: www.youtube.com. Acesso em: 27 nov. 2014. 